\title{
Numerical Two-Dimensional Steady-State Evaluation of the Thermal Transmittance Reduction in Hollow Blocks
}

\author{
Marcelo Adriano Fogiatto ${ }^{1}$, Gerson Henrique dos Santos ${ }^{2, *}$ and João Victor Reia Catelan ${ }^{3}$ \\ 1 Mechanical Engineering Graduate Program, Pontifical Catholic University of Parana-PUCPR, \\ Imaculada Conceição, 1155, 80215-901 Curitiba, Brazil; m.a.fogiatto@gmail.com \\ 2 Mechanical Engineering Graduate Program, Federal University of Technology-Paraná-UTFPR, \\ Monteiro Lobato, km 04, 84016-510 Ponta Grossa, Brazil \\ 3 Mechanical Engineering Department, Federal University of Technology-Paraná-UTFPR, Monteiro Lobato, \\ km 04, 84016-510 Ponta Grossa, Brazil; joaocatelan2@gmail.com \\ * Correspondence: gsantos@utfpr.edu.br; Tel.: +55-429-9112-3032
}

Received: 4 December 2018; Accepted: 29 January 2019; Published: 31 January 2019

\begin{abstract}
After the first concerns about global energy consumption around the $70 \mathrm{~s}$, some standards were established with the aim of improving the energy efficiency in buildings. In this context, according to the US Department of Energy, heating, ventilation, and air conditioning (HVAC) systems comprise about $50 \%$ of the building energy consumption and $20 \%$ of total consumption in the United States. Energy consumption of this kind of equipment depends on several factors, one of the most important factors being the heat transfer through the building envelope. In the walls, hollow concrete blocks have become common in recent years due to advantages such as their strength, their space for pipes and wiring, and fast construction, among others. In order to reduce the thermal load, several forms of insulation were tested on these constructive elements. Thus, effects of the low emissivity, insulating material, radiant shields, and baffles on the inner cavities of the blocks are presented in this paper. Effects of temperature differences between the exterior surfaces on the thermal transmittance and on the combined average heat transfer coefficient inside the cavities are also shown.
\end{abstract}

Keywords: hollow blocks; thermal transmittance; numerical simulations; two-dimensional; steady-state

\section{Introduction}

Building energy consumption usually takes a significant percentage of the total energy consumption. According to BEN 2018 (The Brazilian Energy Balance) [1], energy consumption in residential, commercial, and public sectors represents $15.4 \%$ of the final consumption in Brazil. In the United States, heating, ventilation, and air conditioning (HVAC) systems for buildings comprise about $50 \%$ of the building energy consumption and $20 \%$ of total consumption.

In this context, the heat transfer through the building envelope is one factor that influences the HVAC energy consumption in a crucial way. Choosing the proper material for wall construction is a vital parameter for contributing to the sustainability of construction sectors and providing thermal comfort for the inhabitants [2-5]. The overall performance of the building envelope depends on many factors, such as the thermophysical properties of all materials used in the wall, thickness and material assembly, the adoption of air-gap and its ventilation level, among others. This work focuses on a specific component. In developing countries, hollow concrete blocks have become common in recent years due to advantages such as strength, fast construction, space for pipes and wiring, and the small amount of waste produced during the construction process. 
Several studies have been conducted to understand the phenomenon of heat transfer in hollow blocks. In an interesting study, Cianfrini et al. [6] investigated the impact of insulation filling in hollow blocks and the role played by filling in thermal inertia of walls, and the results showed that for some blocks, a lower front mass can lead to a higher time lag, which is found to describe building performance in the literature. Caruana et al. [7] used 10 different techniques and parameters for measuring the thermal performance of the hollow blocks, describing the differences between them and comparing them with the standard.

Santos and Mendes [8] elaborated a numerical study on heat, air, and moisture transfer through hollow blocks using a model based on three driving potentials described in detail in [9]. They concluded that when the coupled heat, air, and moisture transfer is taken into account, the values of transmittance differ from those obtained by assuming pure conductive heat transfer.

In another analysis, Antar and Baig [10] suggested a new layout in hollow blocks with three cavities for increasing the thermal resistance and used a numerical method to calculate the thermal transmittance. In other work, in order to improve the design of the hollow block, Zhang and Wang [11] presented a simple numerical approach of the heat transfer through a wall with hollow blocks and found that by reducing the rib width and hole number in each row, the thermal performance could be improved. They also recommended an increase in the number of rows of holes rather than hole thickness of a hollow block. It was observed that increasing the block thickness with an increase in hole spacing was more effective than increasing the hole rate. Xamán et al. [12] also performed a numerical study on hollow blocks with and without insulating and reflective materials for roofing. The results showed that a change in the configuration of insulating could improve the thermal insulation by $46.3 \%$.

According to the works found in the literature, several studies are presented with the purpose of reducing the thermal transmittance and consequently increasing the thermal performance of the hollow blocks. However, studies comparing various types of insulation are still barely explored. Thus, effects of the low emissivity, insulating material, radiant shields, and baffles on the inner cavities of the blocks are presented in this paper. Effects of temperature differences between the exterior surfaces on the thermal transmittance and the combined average heat transfer coefficient inside the cavities are also shown.

\section{Materials and Methods}

The thermal transmittance of concrete building blocks was obtained by performing computational fluid dynamics (CFD) simulations, considering two-dimensional steady-state analysis for five different block configurations. These simulations were performed on the software ANSYS Workbench 17.1 using the CFD package ANSYS Fluent 17.1. In this section, the physical domain of the studied blocks, boundary conditions, simulation procedure, thermophysical properties, and mesh validation is presented.

\subsection{Physical Domain}

For all five configurations, the concrete blocks were considered to have the same external dimensions, which were 190-mm length and 390-mm height, the same as the ones provided by the Brazilian regulation [13] for a standard concrete block. Block \#1 was considered as the standard configuration without any form of insulation applied to reduce the thermal transmittance. Block \#2 was considered the low emissivity on the inner surfaces, block \#3 had its cavities filled with insulating material, block \#4 had radiant shields in the middle of its cavities, and block \#5 was conceived with baffles in the inner surfaces. The dimensions of blocks \#1 through \#5 are shown in Figure 1. 


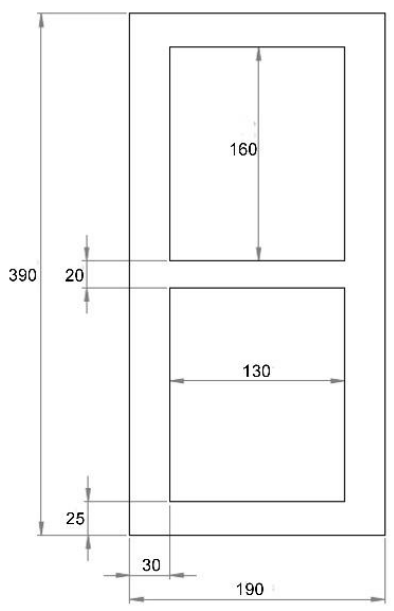

$\# 1$ to \#3

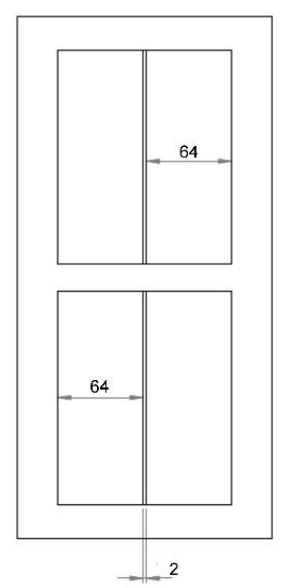

\#4

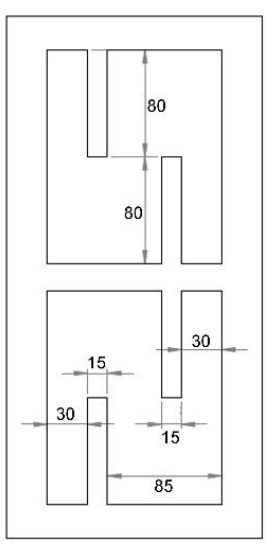

\#5

Figure 1. Dimensions (mm) of the blocks.

\subsection{Boundary Conditions}

Dirichlet and Neumann-type boundary conditions were considered in this study. Two parallel external surfaces were conceived as isothermal, which made it possible for a heat transfer process to occur through the block. The other boundaries were considered as insulated surfaces. These boundary conditions are visualized in Figure 2, where TA and TB are the different constant temperature values. The average temperature value was always $300 \mathrm{~K}$.

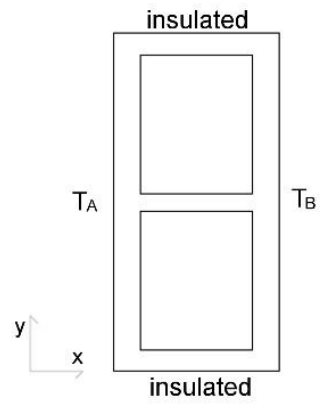

Figure 2. Boundary conditions.

\subsection{Simulation Procedure}

The simulations were performed considering a steady-state condition and laminar flow for the cases where the cavities were filled with air. The thermal radiation inside the cavities was simulated by the discrete ordinates radiation model [14].

As mentioned, five kinds of blocks were considered, each with different methods to reduce the heat transfer intensity. The method used for each block is shown in Table 1. In order to evaluate the effects of temperature differences between external surfaces on the heat transfer, the thermal transmittance was calculated using temperature differences of $5 \mathrm{~K}, 10 \mathrm{~K}, 20 \mathrm{~K}$, and $40 \mathrm{~K}$.

Table 1. Configuration of the blocks.

\begin{tabular}{cccccc}
\hline Measure & \multicolumn{5}{c}{ Block } \\
\hline & $\# 1$ & $\# 2$ & $\# 3$ & $\# 4$ & $\# 5$ \\
Low emissivity coating & - & $X$ & - & - & - \\
Polystyrene filling & - & - & $X$ & - & - \\
Aluminum foil shield & - & - & - & $X$ & - \\
Concrete baffles & - & - & - & - & $X$ \\
\hline
\end{tabular}




\subsection{Thermophysical Properties}

An accurate simulation of air behavior inside the cavities was important in order to obtain credible results. This accuracy depended in part on appropriate air properties informed by the CFD program. The air density, which is an extremely important property for simulating the buoyancy process, was established by the equation of state for real gases developed by Peng and Robinson [15]. The other air properties necessary to simulate the process were obtained from thermodynamic tables [16]. These properties are shown in Table 2.

Table 2. Properties of air as functions of temperature.

\begin{tabular}{cccc}
\hline Temperature & Specific Heat & Thermal Conductivity & Dynamic Viscosity \\
\hline $\mathrm{T}(\mathrm{K})$ & $\mathrm{c}(\mathrm{J} /(\mathrm{kg} \cdot \mathrm{K}))$ & $\mathrm{k}(\mathrm{W} /(\mathrm{m} \cdot \mathrm{K}))$ & $\mu\left(\mathrm{N} \cdot \mathrm{s} / \mathrm{m}^{2}\right)$ \\
\hline 250 & 1006 & 0.0223 & $1.596 \times 10^{-5}$ \\
300 & 1007 & 0.0263 & $1.846 \times 10^{-5}$ \\
350 & 1009 & 0.0300 & $2.082 \times 10^{-5}$ \\
\hline
\end{tabular}

The thermal properties of the solid materials were considered as constant values and obtained from thermodynamic tables [16]. These property values are shown in Table 3. In case \#2, the low emissivity coating was considered to be the same used by Principi and Fioretti [17] with an emissivity value of $\varepsilon=0.5$.

Table 3. Properties of the solid materials at $300 \mathrm{~K}$.

\begin{tabular}{ccccc}
\hline Material & Specific Heat & Thermal Conductivity & Density & Emissivity \\
\hline & $\mathrm{c}(\mathrm{J} /(\mathrm{kg} \cdot \mathrm{K}))$ & $\mathrm{k}(\mathrm{W} /(\mathrm{m} \cdot \mathrm{K}))$ & $\rho\left(\mathrm{kg} / \mathrm{m}^{3}\right)$ & $\varepsilon(-)$ \\
\hline Concrete & 1000 & 1.750 & 2300 & 0.90 \\
Polystyrene & 1210 & 0.027 & 55 & - \\
Extruded & 903 & 237 & 2702 & 0.07 \\
Aluminum & & &
\end{tabular}

\subsection{Mesh Verification}

For this study, we conceived a structured mesh with quadrilateral elements. In the solid region, these elements had a $1 \mathrm{~mm}$ size, and in the fluid regions, a $0.5 \mathrm{~mm}$ size. In numerical simulations, convergence problems and mesh dependence are higher in the air domain than in the solid region. Accordingly, the verification of this mesh was performed by temperature profiles comparison between the considered mesh and a benchmark solution provided by Wakashima and Saitoh [18]. In this benchmark, it was considered a free convection situation in a square cavity with two vertical isothermal surfaces and two horizontal insulated surfaces restraining a flow of Rayleigh number $\mathrm{Ra}=1 \times 10^{6}$. The profiles of the validation test and the benchmark solution are visualized in Figure 3.

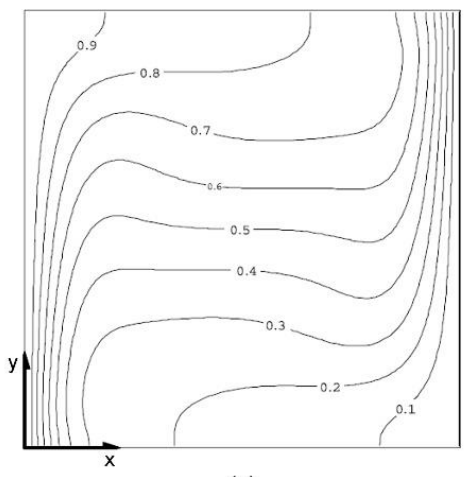

(a)

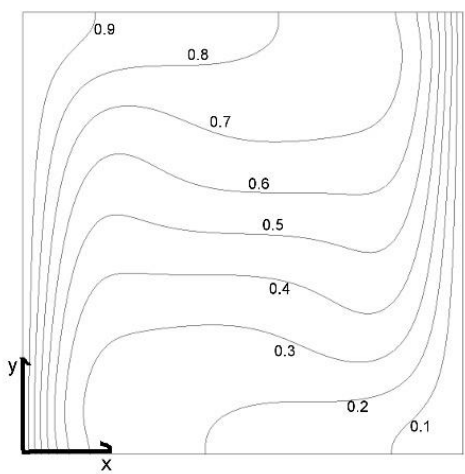

(b)

Figure 3. Temperature dimensionless profiles of the benchmark [18] solution (a) and the mesh pre-test (b). 
It can be seen that the mesh chosen for this study was in agreement with the benchmark solution. In the center of the cavity, by varying the position on the y axis, the maximum difference was $5 \%$ in the temperature dimensionless values. In this case, this mesh was applied to this work because, apart from the acceptability of temperature profiles, the boundary conditions used in this study were similar to those of the benchmark solution.

\section{Results and Discussion}

This section analyzes the effects of different measures applied to reduce the thermal transmittance and the influence of the temperature differences on the transmittance in the case of hollow blocks.

\subsection{Effect of the Measures Applied to Reduce Transmittance}

In the first step, we evaluated the results of thermal transmittance obtained for all the blocks, considering a 20-K temperature difference between the external surfaces. The temperature profiles of blocks \#1 through \#5 for this boundary condition are shown in Figure 4.

The values obtained through the heat transfer simulation for the thermal transmittance $(U)$ and the combined average heat transfer coefficient inside the cavities (h), as well as the reduction in transmittance related to block \#1, are shown in Table 4.

Table 4. Thermal transmittance and combined heat transfer coefficient for $\Delta \mathrm{T}=20 \mathrm{~K}$.

\begin{tabular}{cccc}
\hline Block & $\mathbf{U}\left(\mathbf{W} /\left(\mathbf{m}^{\mathbf{2}} \cdot \mathbf{K}\right)\right)$ & $\mathbf{h}\left(\mathbf{W} /\left(\mathbf{m}^{2} \cdot \mathbf{K}\right)\right)$ & $\mathbf{U}$ reduction $(\%)$ \\
\hline$\# 1$ & 6.07 & 8.85 & - \\
$\# 2$ & 4.91 & 6.97 & 19.1 \\
$\# 3$ & 1.89 & - & 68.9 \\
$\# 4$ & 3.39 & 3.68 & 44.3 \\
$\# 5$ & 4.72 & 5.55 & 22.2 \\
\hline
\end{tabular}

The transmittance value calculated for block $\# 1,6.07 \mathrm{~W} /\left(\mathrm{m}^{2} \cdot \mathrm{K}\right)$, was not far from the value of $5.50 \mathrm{~W} /\left(\mathrm{m}^{2} \cdot \mathrm{K}\right)$ obtained for this block by using the calculation procedure available in international regulation standards [19].

An improvement on the performance of the standard block was observed with the application of the low emissivity coating in the cavities surfaces in case \#2, reducing the cavity heat transfer coefficient and consequently reducing the thermal transmittance. In this case, the thermal transmittance of the hollow block was reduced by $19.1 \%$. For determined multi-holed block geometry with same coating considered, Principi and Fioretti [17] observed a reduction of $19.4 \%$.

The most remarkable result in terms of low heat transfer was obtained from block \#3, which achieved a $68.9 \%$ reduction in thermal transmittance when compared to block \#1. The polystyrene filling of the cavities disabled the effects of free convection and thermal radiation inside of them. These factors added to the low thermal conductivity of polystyrene, allowing the significant reduction. In an experimental study, Pavlik et al. [20] observed a reduction of $32 \%$ in transmittance when filling a hollow block with polystyrene balls. The decrease in transmittance calculated in this study was higher than the experimental value because the original geometry conceived by Pavlik et al. [20] did not provide good conditions for convection and radiation. 

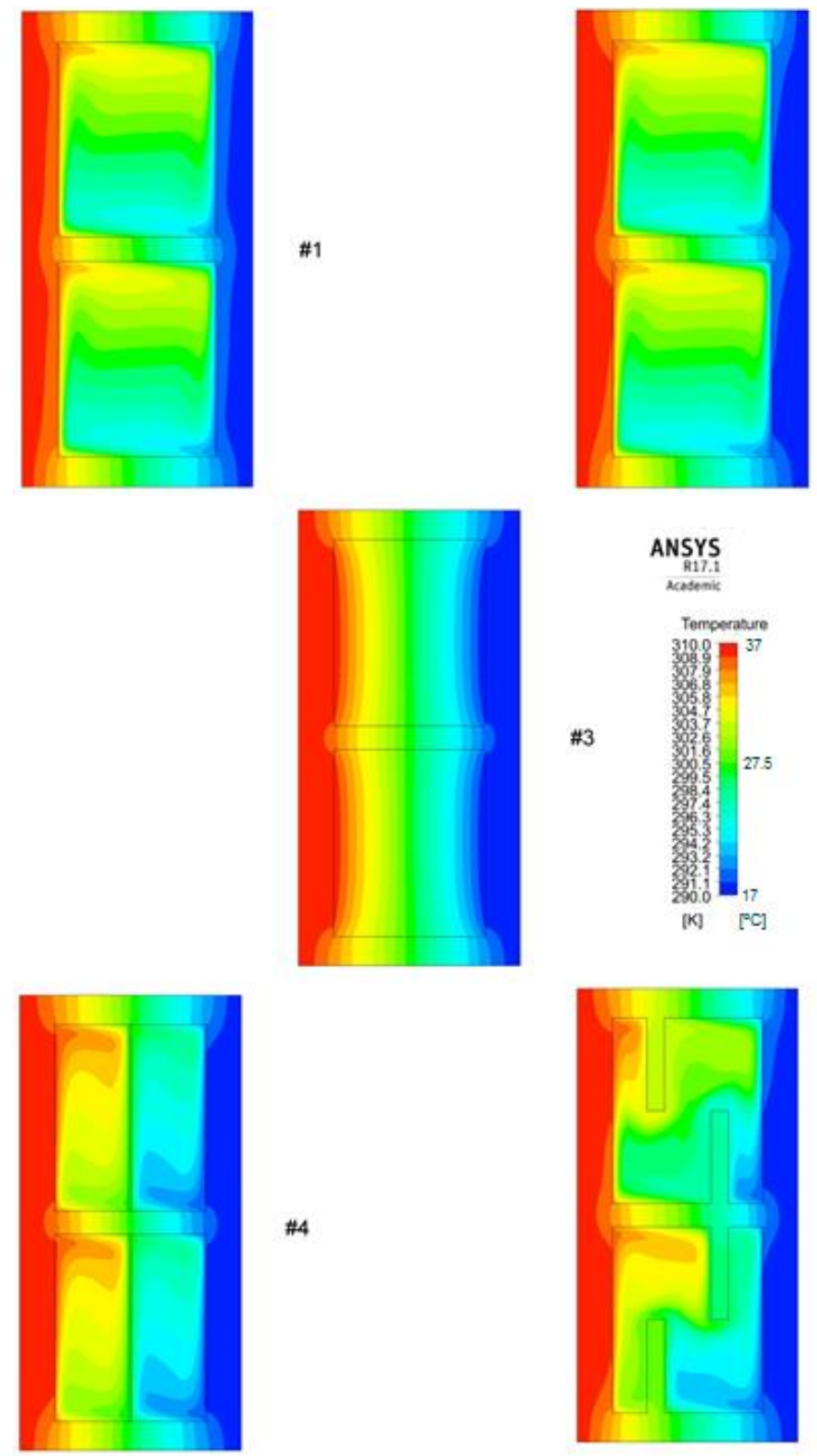

\#4

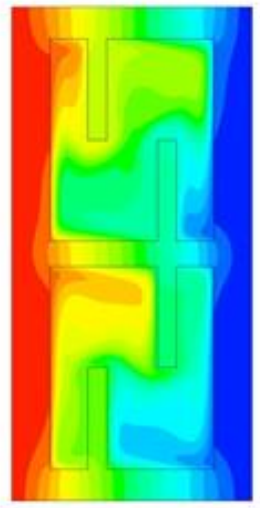

Figure 4. Temperature profiles of blocks \#1 through \#5 for $\Delta \mathrm{T}=20 \mathrm{~K}$.

The second best thermal performance was obtained in the case of block \#4, which had the aluminum foils placed in the center of cavities acting as radiant shields. This case presented a $44.3 \%$ reduction in thermal transmittance and the lowest value of the combined heat transfer coefficient $\left[3.68 \mathrm{~W} /\left(\mathrm{m}^{2} \cdot \mathrm{K}\right)\right]$. This low value reached was due to two factors-the aluminum foil decreased the radiation heat transfer, and the shield acted as a confinement barrier, not allowing the air circulation in high velocities, as observed in Figure 5. These velocity profiles of the air inside the hollow blocks were responsible for the temperature gradients observed in Figure 4.

At last, considering the baffles in the cavities surfaces in case \#5, the reduction calculated in thermal transmittance was $22.2 \%$ when compared to block \#1. These results were very similar to the ones obtained for block \#2. In a similar situation, Alhazmy [21] also observed some reduction in the heat transfer coefficient inside the cavities with the presence of two vertical baffles per cavity (the same method conceived in this study). 

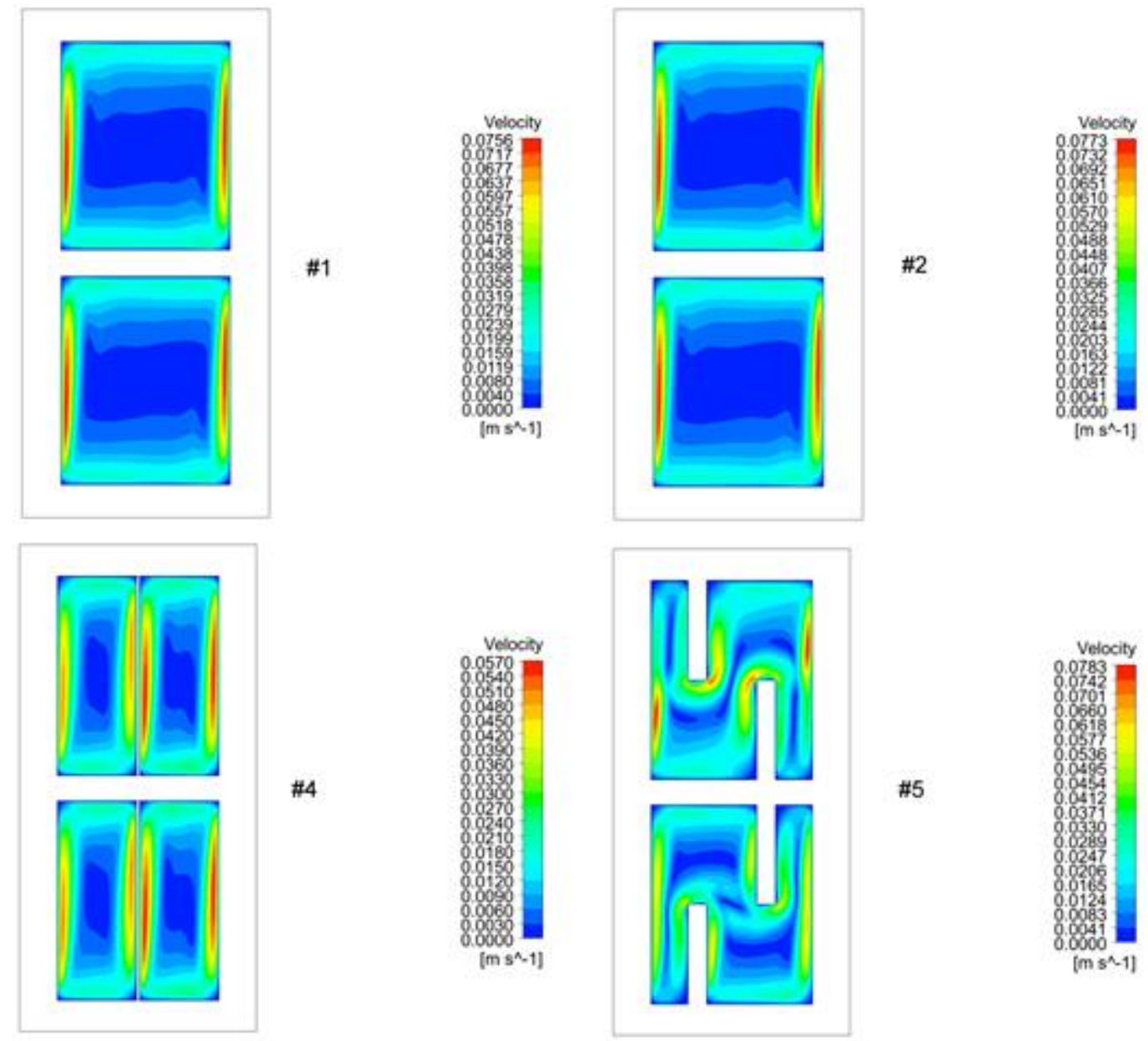

Figure 5. Velocity profiles of air inside cavities for $\Delta \mathrm{T}=20 \mathrm{~K}$.

\subsection{Effect of Temperature Difference on Thermal Transmittance}

The calculated values of thermal transmittance for each hollow block under distinct temperature differences are shown in Table 5.

Table 5. Transmittance of hollow blocks for distinct values of $\Delta \mathrm{T}$.

\begin{tabular}{ccccc}
\hline$\Delta \mathbf{T}(\mathbf{K})$ & \multicolumn{4}{c}{$\mathbf{U}\left(\mathbf{W} /\left(\mathbf{m}^{2} \cdot \mathbf{K}\right)\right)$} \\
\hline & $\# 1$ & $\# 2$ & $\# 4$ & $\# 5$ \\
\hline 5 & 5.61 & 4.41 & 3.15 & 4.33 \\
10 & 5.82 & 4.64 & 3.25 & 4.52 \\
20 & 6.07 & 4.91 & 3.39 & 4.72 \\
40 & 6.42 & 5.29 & 3.54 & 4.97 \\
\hline
\end{tabular}

In all cases, an increase in thermal transmittance due to the increase in temperature difference was observed. In part, this was due to a gain in the free convection effect in the cavity, which was illustrated by the increase in air velocity and is shown in Figure 6.

Besides air velocity, radiation heat transfer also increased with larger temperature differences. In Figure 7, it can be seen that the difference in temperature effects is noticed on the value calculated for the combined average heat transfer coefficient. It should be noted that among all the hollow blocks, aluminum foil shield (\#4) was the one that presented the lowest values under all circumstances. When a larger temperature difference was used (above $37 \mathrm{~K}$ ) between the surfaces and when the effects of thermal radiation were more important, the low emissivity coating (\#2) presented a greater 
potential for the reduction of the heat flow than the concrete baffles (\#5), where the convective effect was predominant.

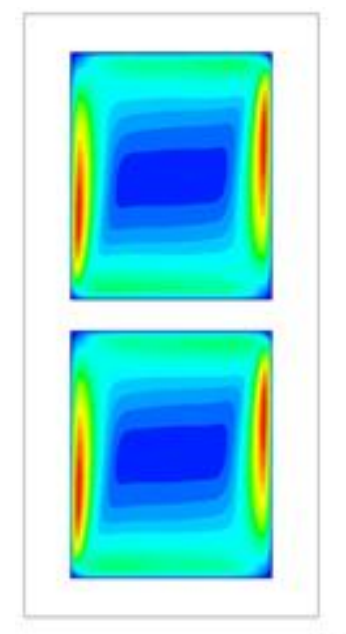

(a)

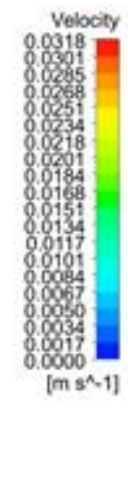

Figure 6. Velocity profiles of air in block \#1: (a) $\Delta \mathrm{T}=5 \mathrm{~K}$; (b) $\Delta \mathrm{T}=40 \mathrm{~K}$.

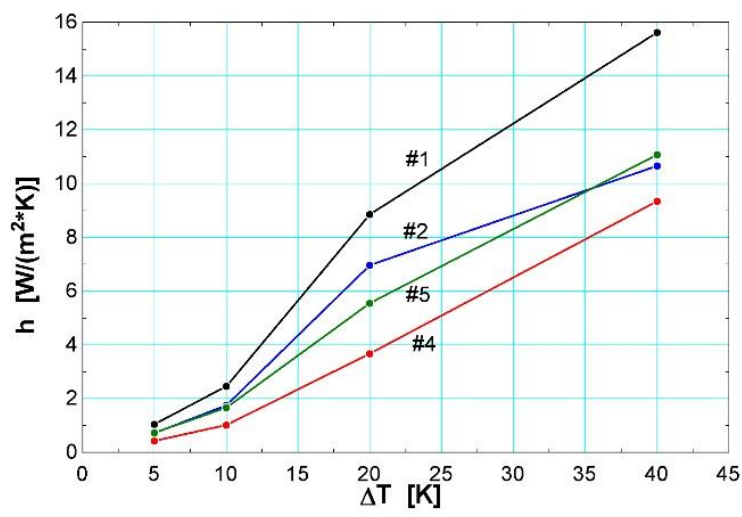

Figure 7. Combined average heat transfer coefficient inside the cavities.

\section{Conclusions}

A numerical two-dimensional steady-state analysis of the effects of some means to decrease thermal transmittance in hollow concrete blocks was performed. Although many factors influence the overall performance of the building envelope - the mortar joints, for example—this work focused on the thermal performance of concrete hollow blocks. Considering 20-K of temperature differences between the external surfaces, an improvement of $19.1 \%$ in the performance of the standard block was observed with the application of the low emissivity coating in the cavities surfaces.

The most remarkable result in terms of low heat transfer was obtained with the polystyrene filling of the cavities, which disabled the effects of free convection and thermal radiation inside of them. The second best thermal performance was obtained with aluminum foils placed in the center of cavities, which acted as radiant shields. This case presented a $44.3 \%$ reduction in the thermal transmittance. At last, when we utilized baffles in the cavities surfaces, the reduction calculated was of $22.2 \%$.

When the effects of temperature differences were verified, an increase in thermal transmittance was observed due to the gain in the free convection and radiation heat transfer.

Considering environmental issues and the results presented in this work, the radiant shields (produced from recyclable material) can be considered an interesting method to obtaining low thermal transmittance in hollow blocks. 
For further work, numerical simulations will compare with experimental tests considering the moisture effects on the thermal performance of hollow blocks.

Author Contributions: M.A.F. implemented the models presented on Section 2, analysed the data and wrote part of the article. G.H.d.S. supervised the work and reviewed the article. J.V.R.C. wrote part of the text.

Funding: The authors thank CNPq (Conselho Nacional de Desenvolvimento Científico e Tecnológico) of the Secretary for Science and Technology of Brazil and Fundação Araucária for the financial support.

Conflicts of Interest: The authors declare no conflict of interest.

\section{References}

1. Ministry of Mines and Energy (Brazil). Brazilian Energy Balance 2018; Empresa de Pesquisa Energética: Brasília, Brazil, 2018.

2. Jelle, B.P.; Gustavsen, A.; Baetens, R. The path to the high performance thermal building insulation materials and solutions of tomorrow. J. Build. Phys. 2010, 34, 99-123. [CrossRef]

3. Perilli, S.; Sfarra, S.; Guerrini, M.; Bisegna, F.; Ambrosini, D. The thermophysical behaviour of cork supports doped with an innovative thermal insulation and protective coating: A numerical analysis based on in situ experimental data. Energy Build. 2018, 159, 508-528. [CrossRef]

4. Madhumathi, A.; Sundarraja, M.C.; Shanthipriya, R. A comparative study of the thermal comfort of different building materials in Madurai. Int. J. Earth Sci. Eng. 2014, 7, 1004-1018.

5. Santos, P.; Martins, C.; Júlio, E. Enhancement of the thermal performance of perforated clay brick walls through the addition of industrial nano-crystalline aluminium sludge. Constr. Build. Mater. 2015, 101, 227-238. [CrossRef]

6. Cianfrini, M.; Vollaro, R.L.; Habib, E. Dynamic thermal features of insulated blocks: Actual behavior and myths. Energies 2017, 10, 1807. [CrossRef]

7. Caruana, C.; Yousif, C.; Bacher, P.; Buhagiar, S.; Grima, C. Determination of thermal characteristics of standard and improved hollow concrete blocks using different measurement techniques. J. Build. Eng. 2017, 13, 336-346. [CrossRef]

8. Santos, G.H.; Mendes, N. Combined heat, air and moisture (HAM) transfer model for porous building materials. J. Build. Phys. 2009, 32, 203-220. [CrossRef]

9. Santos, G.H.; Mendes, N. Heat, air and moisture transfer through hollow porous blocks. Int. J. Heat Mass Transf. 2009, 52, 2390-2398. [CrossRef]

10. Antar, M.A.; Baig, H. Conjugate conduction-natural convection heat transfer in a hollow building block. Appl. Therm. Eng. 2009, 29, 3716-3720. [CrossRef]

11. Zhang, Y.; Wang, Q. Influence of hollow block's structural configuration on the thermal characteristics of hollow block wall. Procedia Eng. 2017, 205, 2341-2348. [CrossRef]

12. Xamán, J.; Cisneros-Carreño, J.; Hernández-Pérez, I.; Hernández-López, I.; Aguilar-Castro, K.M.; Macias-Melo, E.V. Thermal performance of a hollow block with/without insulating and reflective materials for roofing in Mexico. Appl. Therm. Eng. 2017, 123, 243-255. [CrossRef]

13. NBR 6136, Blocos Vazados de Concreto Simples para Alvenaria. 2016. Available online: https://www. abntcatalogo.com.br/norma.aspx?ID=364276 (accessed on 15 January 2019). (In Portuguese)

14. Lu, X.; Wang, T. Investigation of radiation models in entrained-flow coal gasification simulation. Int. J. Heat Mass Transf. 2013, 67, 377-392. [CrossRef]

15. Peng, D.Y.; Robinson, D.B. A new two-constant equation of state. Ind. Eng. Chem. Fundam. 1976, 15, 59-64. [CrossRef]

16. Bergman, T.L.; Lavine, A.S.; Incropera, F.P.; Dewitt, D.P. Fundamentals of Heat and Mass Transfer, 7th ed.; Wiley: Hoboken, NJ, USA, 2011; pp. 983-1011. ISBN 13 978-0470-50197-9.

17. Principi, P.; Fioretti, R. Thermal analysis of the application of pcm and low emissivity coating in hollow bricks. Energy Build. 2012, 51, 131-142. [CrossRef]

18. Wakashima, S.; Saitoh, T.S. Benchmark solutions for natural convection in a cubic cavity using the high-order time-space method. Int. J. Heat Mass Transf. 2004, 47, 853-864. [CrossRef] 
19. International Organization for Standardization (ISO). ISO 6946: Building Components and Building Elements-Thermal Resistance and Thermal Transmittance-Calculation Method; ISO: Geneva, Switzerland, 1996.

20. Pavlik, Z.; Jerman, M.; Fort, J.; Cerny, R. Monitoring thermal performance of hollow bricks with different cavity fillers in difference climate conditions. Int. J. Thermophys. 2015, 36, 557-568. [CrossRef]

21. Alhazmy, M.M. Internal baffles to reduce the natural convection in the voids of hollow blocks. Build. Simul. 2010, 3, 125-137. [CrossRef] 